\title{
Assessment of Small-scale Buffalo Milk Dairy Production-A Premise for a Durable Development
}

\author{
Marian MIHAIU ${ }^{1}$, Alexandra LAPUSAN ${ }^{1 *}$, Romolica MIHAIU², Sorin D. DAN ${ }^{1}$, Carmen JECAN ${ }^{1}$ \\ ${ }^{1}$ University of Agricultural Sciences and Veterinary Medicine, Faculty of Veterinary Medicine, Department of Animal Production \\ and Food Safety, 3-5 Mănăştur Street, Cluj-Napoca; Romania; lapusan_alexandra@yahoo.com (correspondingauthor) \\ ${ }^{2}$ Babes-Bolyai University, Faculty of Economics and Business Administration, Management \\ Department, 58-60 Teodor Mihali Street, Cluj-Napoca, Romania
}

\begin{abstract}
Buffalo husbandry is an important source of income for a number of small-scale producers in Romania that is why an assessment of its' product's quality is much needed for improvement and evaluation of their vulnerability to international competition. In order to ascertain possible developments in the buffalo dairy sector and to broadly identify areas of intervention that favor small-scale dairy producers, the study examined the potential to improve buffalo milk production by evaluating its authenticity and hygienic quality. The methods used involved the molecular testing (PCR-technique) for identifying cow, sheep or goat DNA in the dairy products' samples collected from the small-scale producers market. The hygienic quality of these samples was determined through classical microbiology methods, highly developed techniques (Trek System) and PCR for bacterial species confirmation. The results showed that a high percent (65\%), from the products found were adulterated with other species milk, mostly cow milk. The most commonly falsified buffalo dairy products were the cheese and the traditional product "telemea". The prevalence of the bacterial species identified belonged to Listeria innocua and Listeria welshmeri. The conclusion of this study is the need of a durable development system in this particular dairy chain to improve and assure the authenticity and quality of the small-scale producers' products and their reliability for the consumers.
\end{abstract}

Keywords: adulteration, bacteria, buffalo milk, traditional, quality

\section{Introduction}

It has become a well-known fact that buffaloes can count as an important economic income in many regions where bovines are inadaptable. The buffalo breeding has been a part of Romania country's traditional activity for many years. These rustic animals have been integrated in the Carpathian-Danube area along with the migration of Huns and Hungarians (Stojanovic et al., 2011).

Recently, the interest for buffalo dairy production has increased due to its higher nutritional composition in comparison with bovine dairy products. This "durabledevelopment" of traditional production is now emerging as a needed process in regulatory confidence with respect to food quality, food safety and the infrastructure for producing, processing and delivering food products from the point of origin to the point of sale. That is why, in order to promote the traditionally made buffalo dairy products, there is a need of higher means of authenticity control and hygienic quality. Safety of dairy products made from raw milk (as found on the traditional market) is debated, while it can be made and sold within the European Union, it is still a subject to discussion within the Codex Committee for Food Hygiene (Anonymous, 1996). Based on the identification of hazards and epidemiological evidence (IFST, 1998), the microorganisms of concern in dairy products are Listeria monocytogenes, E. coli O157:H7, Salmonella, and toxin-producing Staphylococcus aureus which may contaminate milk and grow in cheese when milk is not pasteurized. An estimation of the consequences for public health of buffalo raw milk traditional cheese' consumption has not been published.

This study focuses mainly on the evaluation of the buffalo dairy products found on the traditional market in comparison with the ones found in the local hypermarkets. This evaluation comprises the authenticity testing to detect possible adulterations with bovine milk and the hygienic aspect related to the possibility of pathogenic bacteria occurrence in the products processed in traditional households.

\section{Materials and methods}

This research has been carried out on a number of eighty samples of buffalo dairy products: milk, cheese, mozzarella and "telemea". All samples were collected in the recipients, in which they were bought from the market or hypermarket, kept at $+4^{\circ} \mathrm{C}$ until their further analysis.

\section{$D N A$ extraction}

The DNA extraction from the dairy products was performed with the FAST ID (Promega) extraction kit. The 
20

purity and concentration of isolated DNA was determined by measuring the absorbance at $260 \mathrm{~nm}$ and $280 \mathrm{~nm}$ in a UV-VIS spectrophotometer (Nanodrop, ND-1000, Thermo-Scientific, USA).

\section{Simplex and duplex PCR amplification method}

The presence of cow DNA in raw cheese, mozzarella and "telemea" samples from buffalo products was detected through amplification of target sequence of cattle mtDNA loop with a cattle specific primer set: Primer 1/Forward: ACT AGA TCA CGA GCT TGA TCA CCA TGC; Primer 2/Reverse: ATG CCT GGT AAA ATT CAT TAA ATA GCG. In parallel PCR control assays were made using buffalo specific primer set: Primer 1/Forward: ACT AGA TCA CGA GCT TGA TCA CCA TGC; Primer 2/Reverse: GTT ATG TGT GAG CAT GGG CTG ATT GGA (Sachinandan et al., 2011). All PCR amplification was performed in a $25 \mu \mathrm{l}$ reaction volume, containing $12.5 \mu \mathrm{l}$ MasterMix (Bioline) containing $\mathrm{MgCl}_{2}$, $\mathrm{dNTP}$ and Taq polymerase, $1 \mu \mathrm{l}$ of each primer (Forward and Reverse), $4 \mu \mathrm{l}$ of template DNA and $6.5 \mu \mathrm{l}$ of PCR Water Grade (Sigma). The PCR cycling parameters were programmed as follows: denaturation at $95^{\circ} \mathrm{C}$ for $30 \mathrm{~s}$, annealing at $65^{\circ} \mathrm{C}$ temperature gradually reduced with $1^{\circ} \mathrm{C}$ until it reached $55^{\circ} \mathrm{C}$. At $55^{\circ} \mathrm{C}, 25$ cycles were used. The extension step was performed at $72^{\circ} \mathrm{C}$ for $10 \mathrm{~min}$.

The duplex PCR was performed using the same primers, given the fact the forward primer is common to both species, in a $25 \mu \mathrm{l}$ reaction volume containing: $12.5 \mu \mathrm{l}$ MasterMix (Bioline) containing $\mathrm{MgCl}_{2}$, dNTP and Taq polymerase, $1 \mu \mathrm{l}$ of each primer (forward and 2 reverse), $4 \mu \mathrm{l}$ of template DNA and $5.5 \mu \mathrm{l}$ of PCR Water Grade (Sigma). The PCR cycling parameters were programmed as follows: initial denaturation at $95^{\circ} \mathrm{C}$ for 1 minute followed by 35 cycles of the three main steps: denaturation: $95^{\circ} \mathrm{C} 30 \mathrm{~s}$, annealing $58^{\circ} \mathrm{C} 25 \mathrm{~s}$, extension $72^{\circ} \mathrm{C} 5$ minutes. Aliquots of $7 \mu \mathrm{l}$ amplified products were electrophoresed on agarose (2\%) gels and stained with GelGreen $(0.5 \mu \mathrm{g} /$ $\mathrm{ml}$ ) after which they were visualized by gel documentation system (BioRad).

\section{The microbiological assessment methods}

Classical methods: The identification of pathogenic bacteria was performed according to the international standards using selective enrichment broths. The ISO 11290 method, used for Listeria spp. identification had a two-stage enrichment process: the dairy product was first enriched in half Fraser (4.104) broth for $24 \mathrm{~h}$, then an aliquot was transferred to full strength Fraser (4.105) broth for further enrichment at $37^{\circ} \mathrm{C}, 48$ hours. Both primary and secondary enriched broth were plated on OXFORD (4.108) and PALCAM agars for 24 hours, in aerobe conditions at $37^{\circ} \mathrm{C}$. For the identification of Staphylococcus spp. the steps were performed according to the SR EN ISO 6888-1,2/2002 AC/2005. The strains were isolated using Baird Parker agar with a rabbit plasma fibrinogen supplement (Biolife, Milan, Italy) incubated at $37^{\circ} \mathrm{C}$ for 24-48 $\mathrm{h}$ to detect coagulase positive staphylococci. For the detection of Bacillus cereus, the protocol was performed according to the SR EN 7932/2003 standard, the selective environment used being MYP (mannitol egg yolk polymixin agar), incubated at $30^{\circ} \mathrm{C}$, for 24 hours.

Confirmation methods: The confirmation of Listeria, Staphiloccocus and Bacillus was made with the help of a rapid analysis system: TREK SYSTEM, which has a simple and rapid protocol that allows the confirmation in maximum 24 hours from the obtaining of the colonies. For the confirmation of Listeria spp. bacteria, the PCR method was also used with the help of Listeria Genus Primer Set (Bio Scientific).

The statistical analysis: was performed using the operating Windows 7 system, Origin program 7.0. The statisticintegrated test was the monofactorial ANOVA system.

\section{Results and discussion}

\section{Product authentication}

As shown in Fig. 1, the majority of the samples collected from the traditional market were mixed with bovine milk. From the total number of samples collected from the free market, a very high percentage (89\%) was found to be adulterated with cow milk. The highest percentage of adulteration was found at cheese and "telemea" (87\%) while the lowest percentage in raw milk (23.2\%).

The primers produced only specie specific amplification and no false positive amplification was observed in related species. Buffalo specific primers amplified an expected 226bp fragment from buffalo DNA (Fig. 2). When

\section{L1 L2 L3 L4 L5 L6 L7 L8 L9 L10 L11 PC NC}

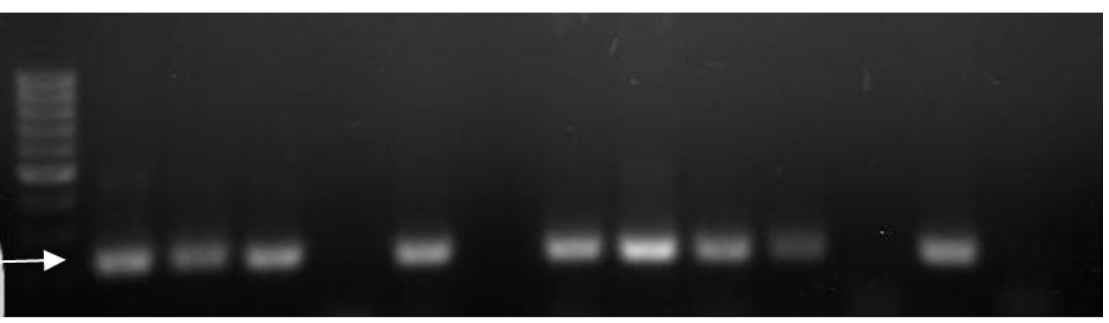

Fig. 1. PCR amplification result with bovine specific primers. Samples are: Marker (M), buffalo milk (L1), buffalo cheese (L2-L5), buffalo "telemea" (L6-L11), positive control (PC); negative control (NC) 


\section{$\begin{array}{lllllllllll}M & \text { L1 } & \text { L2 } & \text { L3 } & \text { L4 } & \text { L5 } & \text { L6 } & \text { L7 } & \text { L8 } & \text { L9 } & \text { PC }\end{array}$}

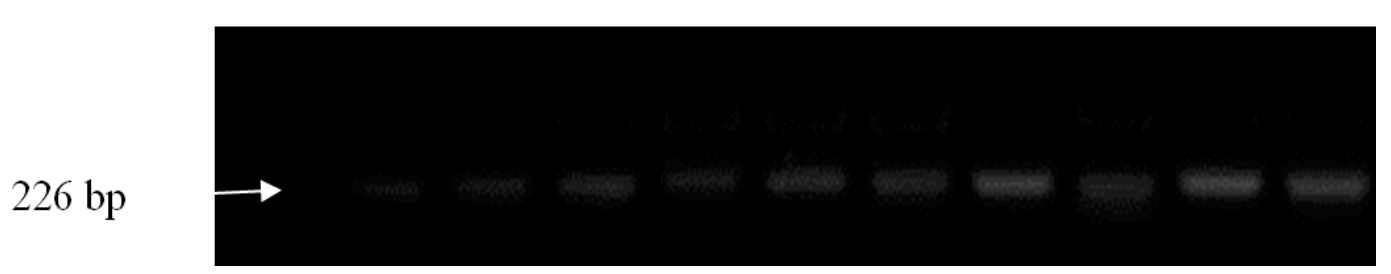

Fig. 2. PCR amplification result with buffalo specific primers. Samples are: Marker (M), buffalo milk (L1), buffalo cheese (L2-L5), buffalo "telemea" (L6-L9), positive control (PC)

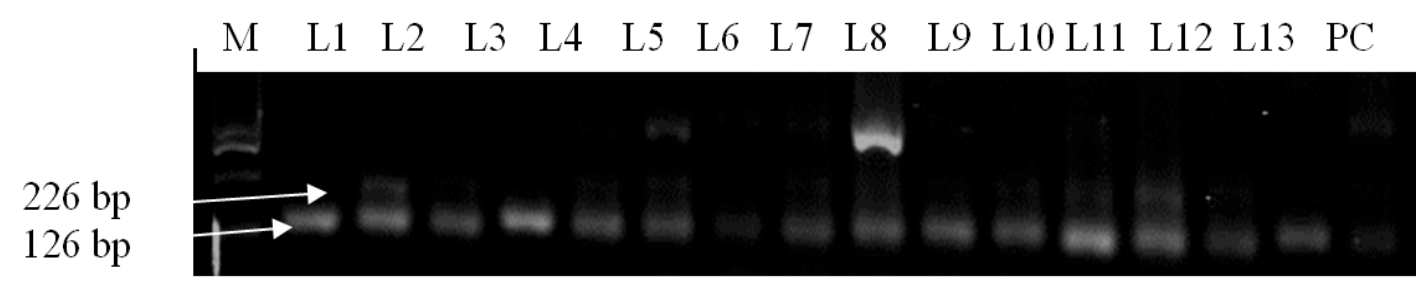

Fig. 3. PCR amplification result with buffalo and bovine specific primers. Samples are: Marker (M), buffalo milk (L1-L4), buffalo cheese (L5-L9), buffalo “telemea” (L10-L15), positive control (PC)

performing the duplex PCR at samples collected from hypermarket, most of them (Fig. 3) were also adulterated, and surprisingly the buffalo DNA has shown less visibility than the bovine one, which could mean that it was even in lesser quantity. Also, as reported by Rea et al. (2001), the amount of DNA recoverable from milk and cheese is directly related to the somatic cell content of the raw milk, and also to the strength of the technique used to process the product, as this can influence the yield, integrity and extractability of the DNA (Fig. 2, Fig. 3).

Similar, in a study conducted on fifteen buffalo mozzarella products, purchased on the Austrian market from various sources (several different market stalls, delicatessen shops and supermarkets), contained substantial amounts of bovine $\beta$-lacto globulin (Czerwenka et al., 2010). The number of adulterated samples found in hypermarkets was surprisingly even higher (92\%) than the one found on the traditional market, and a more effective technique, which can detect the quantity of DNA (RT-PCR) is needed in order to properly assess this problem. Adulteration of buffalo' milk by addition of cow' milk or even substitution with cow' milk is a common practice also on Egypt market (Darwish et al., 2009).

\section{Microbiological assessment}

After investigating the milk samples collected from the traditional market, the following results were obtained (Tab. 1). The highest percentage of bacteria found in this type of product belonged to Listeria spp. The confirmation of Listeria spp. in these products was made through PCR and Trek System (Tab. 1).

Comparing the results of these bacteria prevalence on the traditional market with the samples collected from hypermarkets, it has been found out that there are significant differences $(p<0.001)$. In the milk samples collected from the hypermarkets, none of the mentioned bacteria found on the traditional market could be detected. A very important cause is the fact that on the specialized markets, milk is sold only after proper processing (pasteurization) preventing the occurrence of microorganisms. Of great concern is also the fact that in the traditional system, the pathogenic Bacillus cereus was found in two samples of raw milk. Most of the bacteria found in the samples collected from the free market are not pathogenic to humans. A study made in India indicated that the dominant microbial flora associated with raw buffalo milk samples, were in the following order: Lactobacillus spp., Staphylococcus aureus, Escherichia coli, Bacillus spp., Pseudomonasfluorescens, Salmonella spp. (Mubarack et al., 2010). The presence of those bacteria in milk suggested contamination from various sources, such as animal, human, environment, utensils and others (Murphy and Boor, 2000).

At the diary product samples collected from the traditional market, no pathogenic bacteria were found and the frequency of non-pathogenic bacteria from the Listeria spp. was much lower (0.2\%). Another study conducted on raw milk samples, collected in farms in Mexico City by

Tab. 1. Microorganisms isolated from buffalo raw milk

\begin{tabular}{ccc}
\hline Microorganism & $\begin{array}{c}\text { No. of positive } \\
\text { samples }\end{array}$ & $\begin{array}{c}\text { Percentage } \\
(\%)\end{array}$ \\
\hline Staphylococcus intermedius & 2 & 5 \\
Staphylococcus chromogenes & 1 & 2.5 \\
Staphylococcus caprae & 1 & 2.5 \\
Staphylococcus aureus & 0 & 0 \\
Bacillus cereus & 2 & 5 \\
Listeria ivanovii & 10 & 25 \\
Listeria welshmeri & 13 & 32.5 \\
Listeria monocytogenes & 0 & 0 \\
\hline
\end{tabular}


22

Vazquez-Salinas et al. (2001), has shown the presence of Listeria spp. in a high rate, even of $L$. monocytogenes (13\%), L. ivanovii (6\%) and L. seeligeri (4\%). Even though in the present study the presence of $S$. aureus was not detected, a study conducted in China established an average load of S. aureus of $1.68 \pm 0.19 \log \mathrm{cfu} / \mathrm{ml}$ in positive samples and the presence of Listeria spp. was not detected in any of the samples (Han et al., 2007). Fook et al. (2004) reported considerably higher levels of $S$. aureus in raw cow milk, with $35 \%$ of the samples having $4.2 \mathrm{log} \mathrm{cfu} / \mathrm{ml}$.

Statistically, analyzing the obtained results significant differences $(p \leq 0.05)$ among the number of bacteria isolated from products and raw milk were found, the highest level being found in the last mentioned. The Listeria spp. isolation frequency was significantly different $(p \leq 0.05)$ at the raw milk samples collected from the traditional market than the one found at the industrial processors (hypermarkets).

\section{Conclusions}

The analysis of a range of commercial buffalo dairy products from various sources showed that adulterated buffalo products are present on the Romanian market and that appropriate monitoring is required to prevent consumer deception. In addition, the achievement of hygiene in buffalo dairy small scale farms directly influences the production oriented economic results and health safety perspectives in human beings. It is therefore critically important to ensure high quality buffalo raw milk production from healthy animals under good hygienic conditions and to apply control measures to protect human health. Therefore, it can be recommend that training and guidance should be given to farm' owners and their workers responsible for buffaloes' milking. Meanwhile, information on health hazards associated with contaminated or adulterated raw milk should be extended to the public, so that consumption of improperly processed dairy products could be avoided.

\section{Acknowledgements}

This study has been financed by the National Council of Scientific Research of Higher Education, Romania, Ideas Project no. 1083/2009.

\section{References}

Anonymous (1996). Report of the $28^{\text {th }}$ Session of the Codex Committee on Food Hygiene, Codex Alimentarius Commission, ALINORM 97/13, Rome.
Czerwenka C, Muller L, Lindner W (2010). Detection of the adulteration of water buffalo milk and mozzarella with cow's milk by liquid chromatography-mass spectrometry analysis of $\beta$-lactoglobulin variants. Food Chem 122:901-908.

Darwish SF, Allam HA, Amin AS (2009). Evaluation of PCR assay for detection of cow's milk in water buffalo's milk. World Appl Sci J 7(4):461-467.

Fook YC, Aminah A, Mohd KA (2004). Bacteriological quality and safety of raw milk in Malaysia. Food Microbiol 21:535541.

Han BZ, Meng Y, Li M, Yang YX, Ren FZ, Zeng QK, Nout MJR (2007). A survey on the microbiological and chemical composition of buffalo milk in China. Food Control 18:742-746.

IFST (1998). Institute of Food Science and Technology. http:// www.easynet.co.uk/ifst/hottop.htm.

Mubarack HM, Doss A, Dhanabalan R, Balachander S (2010). Microbial quality of raw milk samples collected from different villages of Coimbatore District, Tamilnadu, South India. Ind J Sci Technol 3(1):61-63.

Murphy SC, Boor KJ (2000). Trouble shooting sources and causes of high bacteria counts in raw milk. Dairy Food Environ Sanitation 20(8):606-611.

Rea S, Chikuni K, Branciari R, Sangamayya RS, Ranucci D, Avellini P (2001). Use of duplex polymerase chain reaction (duplex-PCR) technique to identify bovine and water buffalo milk used in making mozzarella cheese. J Dairy Res 68:689-698.

Sachinandan D, Brahma B, Polley S, Mukherjee A, Banerjee D, Gohaina M, Singh KP, Singh R., Datta TK, Goswami SL (2011). Simplex and duplex PCR assays for species specific identification of cattle and buffalo milk and cheese. Food Control 22:690-696.

Stojanovic S, Ivanov S (2011). International Workshop on Conservation of Autochthonous Buffalo, SAVE Foundation, 06-07, Sighisoara, Romania.

Vazquez-Salinas C. Rodas-Suárez O, Qumnonez-Ramirez EI (2001). Occurrence of Listeria species in raw milk in farms on the outskirts of Mexico City. Food Microbial 18:177181. 